\title{
A mathematical model for predicting the outcome in moderate head injury
}

\author{
U. S. Srinivasan \\ Department of Neurosurgery, PSG Institute of Medical Sciences, Coimbatore and MIOT Hospitals, Chennai, India
}

\begin{abstract}
Background: Virtually all the literature on head injury has focused on the outcome prediction of severe and mild head injuries and very few studies have been dedicated to patients sustaining moderate head injuries. Aim: To identify the patient following moderate head injury who may die, develop severe disability or significant cognitive and behavioral problems on the first day of injury itself. Setting: Tertiary teaching hospital. Design: Prospective study divided into two groups. Materials and Methods: The study included 85 patients whose Glasgow coma scale score were 9-12 and who had isolated moderate head injury. Among the above patients a preliminary prospective study was conducted in first group of 64 patients using 7 clinical factors, 18 neuro-behavioral sequel and CT brain data in prediction of outcome with moderate head injury. From the results obtained in the above study three statistically significant factors were identified and a mathematical model was developed and used prospectively in the next 21 patients and its accuracy was evaluated. Statistical Methods Used: Multiple regression analysis and Kendall's tau non- parametric test using statistical package for social sciences (SPSS 11-5-version) were used to find out the predictive factors. Results: Results of these patients showed combination of CT scan brain data, verbal response and neurological signs could provide a reliable prediction in moderate head injury. Conclusion: Based upon the above results a mathematical model was developed giving a value for the above-mentioned factors. The mathematical model was "CT brain data $\times$ (Verbal response + Neurological Signs)". Its overall accuracy when used on the day of admission was around $80 \%$.
\end{abstract}

Key words: Moderate head injury, traumatic brain injury, computed tomographic data, glasgow coma scale, neurological signs.

\section{Introduction}

Even though the term moderate head injury is used, mortality does occur among these cases. A careful analysis of these cases reveals significant impairment of their higher neurological function and in particular their cognitive functions. ${ }^{[1,2]}$ Very few studies has been dedicated to patients sustaining moderate head injuries ${ }^{[3,4]}$ Hence this study aims to develop mathematical model that will identify the patient who may die, deteriorate neurologically or develop neurobehavioral sequel lasting more than 3 months following moderate head injury.

\section{Materials and Methods}

During the period January 1997 to September 2004, 85 patients with isolated moderate head injuries with Glasgow Coma Scale (GCS) score of 9-12 were only included in the study. ${ }^{[1,2,5]}$ The study did not include patients with multiple extracranial severe injuries, pediatric head injuries, isolated depressed fracture, addiction to alcohol or drugs, known psychiatric disorder or mental retardation, preexisting terminally ill disease. The study was a prospective study. It was divided into two parts. Among the 85 patients studied a preliminary prospective study was conducted in first group of 64 patients using 7 clinical factors, 18 neurobehavioral sequel and CT brain data in prediction of outcome with moderate head injury. These groups of patients are labeled as group A. From the results obtained in the above study three statistically significant factors were identified and a mathematical model was developed and used prospectively in the next 21 patients and its accuracy was evaluated. These groups of patients are labeled as group B. Age of the patients varied from 18 years to 87 years and the mean age is 40.72 years. The following eight clinico-radiological parameters were analyzed at the time of admission in the first 64 patients - 1. Mode of injury 2. Duration of loss of consciousness (LOC) 3. Duration of Post Traumatic Amnesia (PTA) 4. Motor response (MR) 5. Verbal response (VR) 
6. Eye opening (EO) 7. Neurological signs (NS) and 8. Computed Tomography scan data (CT). The focal neurological signs may be pupillary inequality, any cranial nerve paresis, monoparesis, hemiparesis and or extensor plantar.

CT scan of brain was done in all 85 patients at the time of admission. The CT scan brain data was divided into following groups for analysis 1. Normal study 2. Diffuse brain injury (DBI) 3. Presence of single mass lesion 4. Presence of multiple mass lesions on one side of cerebral hemisphere 5 . Presence of multiple mass lesions on both sides of brain. Diffuse brain injuries include injuries where there is no visible mass lesion on CT scan but the basal cisterns and ventricles may be distorted and midline shift may or may not be present. The mass lesions on CT scan can be epidural haematoma, acute subdural hematoma, contusion or intracerebral hematoma. The following neurobehavioral sequelae were analyzed using a standard protocol 1 . headache 2 . giddiness 3. vertigo 4. fatigability 5 . blurred vision 6 . sleep disturbance 7 . depression 8 . anxiety 9 . appetite 10 . coordination 11 . restlessness 12. generalized pain 13 . ear pain/tinnitus 14 . inability to work 15. attention span and the immediate recall memory were tested using the digit repetition test 16 . vigilance was tested using the random letter test 17 . visual pattern and alternating motor pattern tests were used to assess the frontal lobe dysfunction.18. Remote memory was tested not only by asking the patient to recall both personal and historical facts but also by the patient's ability to recollect four unrelated words, verbal story for immediate recall, visual memory for hidden objects, visual design reproduction and paired associate learning. All these were tested as per the criteria suggested by Strub et al. ${ }^{[6]}$ Clinical evaluation was done in patients at the end of 1, 7, 30 days, 3 and 6 months. The Glasgow outcome scale was used to assess the final outcome at the end of three months in this study. ${ }^{[7]}$

All the moderate head injury patients were initially treated with anti-edema drugs Injection Frusemide and Injection 20\% Mannitol in standard doses. In all patients CT brain was done immediately after admission. Follow up CT brain was done after 48 hours or if neurological deterioration occurred. Patient who had significant mass lesion with mass effect was immediately operated. Anticonvulsant Injection Diphenylhydantoin was given for all the patients. The antiedema drugs were tapered and stopped. Patients whose GCS score deteriorated to below $9(<=$ 8 ) from the original admission GCS score or after surgery were intubated and ventilated. Among 12 cases who received injection Dexamethasone 8 had been given steroids in other hospitals. Nimodipine was not given to any of the patients. Detailed clinical and neuropsychological examination was done at the end of 30 days, 3 and 6 months. As a protocol all head injury patients were referred to the psychologist for detailed work up and counseling. This study does not contain any new drug or device and the above therapeutic strategy is the same management that is being followed in the neurosurgical centers.

In addition to the multiple regression analysis which is a parametric statistical test, considering the fact that all independent and dependent variables are measured on a single ordinal scale non-parametric test Kendall's tau correlation test was also used to analyze the data of 64 patients in group A with above mentioned 8 variables to identify the significant predictive factors. The results of both the above statistical methods were obtained using statistical package for social sciences (SPSS 11-5 version). Based upon the results, a mathematical model is developed and its accuracy in predicting the outcome is analyzed.

\section{Results}

The outcome of moderate head injury (Dependent Variable 9) has been compared with 8 independent variables that have been listed above using two different statistical methods in-group A patients. When multiple regression analysis was used it was found that CT (0.472), VR (0.384) and NS (0.433) are three statistically significant variables [Table 1 and 2 ]. The regression

\begin{tabular}{|c|c|c|c|c|c|c|c|c|c|}
\hline & \multicolumn{2}{|c|}{$\begin{array}{c}\text { Unstandardized } \\
\text { coefficients }\end{array}$} & \multicolumn{2}{|c|}{$\begin{array}{c}\text { Standardized } \\
\text { coefficients }\end{array}$} & \multirow[t]{2}{*}{$\mathbf{T}$} & \multirow[t]{2}{*}{ Sig. } & \multicolumn{2}{|c|}{$\begin{array}{c}95 \% \text { confidence } \\
\text { interval for } \mathrm{B}\end{array}$} & \multirow{2}{*}{$\begin{array}{l}\text { V9 outcome } \\
\text { pearson } \\
\text { correlation }\end{array}$} \\
\hline & Mean & B & S. E & Beta & & & Lower & Upper & \\
\hline (Constant) & 1.77 & 0.310 & 0.451 & & 0.688 & 0.495 & -0.594 & 1.215 & - \\
\hline V1 INJURY & 2.06 & -0.207 & 0.179 & -0.122 & -1.155 & 0.253 & -0.566 & 0.152 & -0.165 \\
\hline V2 LOC & 1.95 & -0.032 & 0.127 & -0.034 & -0.254 & 0.800 & -0.286 & 0.222 & $0.266^{*}$ \\
\hline V3 CT & 1.39 & 0.227 & 0.119 & 0.265 & 1.916 & 0.061 & -0.010 & 0.465 & $0.472^{\star *}$ \\
\hline V4 MR & 2.47 & 0.308 & 0.142 & 0.247 & 2.162 & 0.035 & 0.023 & 0.593 & $0.304^{*}$ \\
\hline V5 VR & 1.78 & 0.175 & 0.082 & 0.270 & 2.149 & 0.036 & 0.012 & 0.339 & $0.384^{\star *}$ \\
\hline V6 EO & 2.84 & -0.208 & 0.097 & -0.248 & -2.141 & 0.037 & -0.403 & 0.013 & -0.049 \\
\hline V7 PTA & 2.11 & 0.209 & 0.079 & 0.278 & 2.654 & 0.010 & 0.051 & 0.367 & $0.278^{*}$ \\
\hline V8 NS & 1.72 & 0.148 & 0.114 & 0.155 & 1.291 & 0.202 & -0.081 & 0.377 & $0.433^{* *}$ \\
\hline
\end{tabular}

a Dependent Variable: V9 OUTCOME Sig: Significance S. E: Standard Error V: Variable

${ }^{*}$ Correlation is significant at the 0.05 level (1-tailed). $r(5 \%)=0.246$

${ }^{* *}$ Correlation is significant at the 0.01 level (1-tailed). $r(1 \%)=0.312$

The $R$ is $0.687 a$ and $R$ square value is 0.472 , adjusted $R$ square is 0.395 with standard error of 0.562 .

The $\mathrm{F}$ change value is 6.141 , probability is $0.0000^{* *}$

The sum of squares and cross products is 32.938 and covariance is 0.523 .

Durbin Watson test value is 1.627 .

Regression model equation is $P=1+\mathrm{e}^{(0.472+0.227 \times 1+0.175 \times 2+0.148 \times 3)-1}$ 
Table 2: Comparison of the correlation results obtained using multiple regression analysis and Kendall's tau test in 64 patients

\begin{tabular}{|c|c|c|c|c|c|c|c|c|c|}
\hline Statistical method & & V1 injury & V2 LOC & V3 CT & V4 MR & V5 VR & V6 EO & V7 PTA & V8 NS \\
\hline $\begin{array}{l}\text { Parametric test - } \\
\text { Multiple regression }\end{array}$ & $\begin{array}{l}\text { V9 outcome } \\
\text { Pearson correlation }\end{array}$ & -0.165 & $0.266^{*}$ & $0.472^{* *}$ & $0.304^{*}$ & $.384^{\star *}$ & -0.049 & $0.278^{*}$ & $0.433^{\star *}$ \\
\hline \multirow{3}{*}{$\begin{array}{l}\text { Non-parametric } \\
\text { Test-Kendall's } \\
\text { Tau test }\end{array}$} & Sig. (1-tailed) & 0.096 & 0.017 & 0.000 & 0.007 & .001 & 0.349 & 0.013 & 0.000 \\
\hline & $\begin{array}{l}\text { V9 outcome } \\
\text { Correlation coefficient }\end{array}$ & -0.01 & $0.263^{*}$ & $0.449^{* *}$ & $0.323^{* \star}$ & $0.340^{* *}$ & 0.0 & $0.230^{*}$ & $0.417^{* *}$ \\
\hline & Sig. 1 tailed & 0.281 & 0.011 & 0.000 & 0.003 & 0.001 & 0.427 & 0.022 & 0.000 \\
\hline
\end{tabular}

${ }^{*}$ Correlation is significant at the 0.05 level (1-tailed)

${ }^{* *}$ Correlation is significant at the 0.01 level (1-tailed)

model equation that was developed is $P=1+\mathrm{e}^{[.472+0.227 \times 1+0.175}$ $\times 2+0.148 \times 3]^{-1}$ where 0.472 is the coefficient of determination $(r$ square), X1 is CT, X2 is VR and X3 is NS. The coefficient of determination when tested for its significance by using anova was also found to be significant at $1 \%$ level of significance. The Durbin Watson test value of 1.627 also indicated that the auto correlation was also present for these variables. Results comparing multiple regression analysis and non-parametric Kendall's tau correlation test are tabulated in [Table 2]. Using both methods of statistical analysis it is found that same variables Computed Tomography scan (CT) (0.472/0.449), Neurological Signs (NS) (0.433/ $0.417)$ and Verbal Response (VR) $(0.384 / 0.340)$ are three most important statistically significant variables [Table 2].

The above regression equation usage needs calculator and it is tedious, hence a simple mathematical model was developed based upon the above results. A value was given for each parameter depending upon the prognostic importance of the factor in predicting the outcome [Table 3]. A simple equation was developed which is given in [Table 3] and the accuracy of it in 64 patients is below reported in [Table 4]. The same model was used prospectively in the next 21 patients belonging to group B and its accuracy was evaluated [Table 4].

The overall accuracy of the equation in the first 64 patients ingroup A was 79.7\% (51/64) compared to $85.7 \%$ (18/21) ingroup B when it was used prospectively in the next 21 patients. The respective mortality was $6.25 \%$ (4/64) in group A compared to $4.7 \%$ (1/21) in group B. Similarly $28.1 \%$ (18/64) patients were operated in the group A with accurate prediction made in $83.3 \%$ cases $(15 / 18)$ while it was $19.1 \%$ (4/21) patients who were subjected to surgery in the group B. In the group A $30 \%$ (18/60) developed persistent neuropsychological sequelae excluding the 4 patients who had expired while in the group B it was $40 \%$ (8/20) excluding the single case that expired.

In order to illustrate the use of equation, consider a patient having a GCS score of 12 who has localizing pain (MR-5), disorientation (VR-4) and eye opening to loud voice (EO-3). Neurological evaluation reveals he has an extensor plantar and CT brain showing a right frontal contusion. Using this mathematical model by substituting the values for the response from the above table viz,

CT: 3 (Single right frontal lobe contusion)
Table 3: The mathematical model with values for the three variables and the final outcome

Equation: Computed Tomography (CT) brain data $x$ $(($ Verbal response $($ VR) + Neurological signs $(\mathrm{NS}))=$ Final Outcome

\begin{tabular}{lc}
\hline CT brain data: & Score \\
Variable & \\
Normal & 5 \\
Diffuse brain injury & 4 \\
Single mass lesion & 3 \\
Multiple unilateral mass lesions & 2 \\
Multiple bilateral mass lesions & 1 \\
Verbal Response (VR) as given in Glasgow Coma Scale \\
Variable & Score \\
Oriented & 5 \\
Disoriented & 4 \\
Inappropriate & 3 \\
Incomprehensible & 2 \\
Nil & 1
\end{tabular}

$\begin{array}{lc}\text { Neurological Signs (NS) } & \\ \text { Variable } & \text { Score } \\ \text { Absent } & 3 \\ \text { Single sign } & 2 \\ \text { Multiple signs } & 1\end{array}$

Final outcome: CT x (VR + NS)

Final value Outcome

$<=3 \quad$ Dead / Severe Disability/ Persistent Vegetative State

4-18 Moderate recovery (Neuropsychological sequel / Surgical intervention)

$>=19 \quad$ Good recovery

VR: 4 (Substituted directly from Glasgow Coma Score)

NS: 2 (Single neurological sign of plantar extensor on one side) The final score: $\mathrm{CT} \times(\mathrm{VR}+\mathrm{NS})=3 \times(4+2)=18$. A final score of 18 is obtained indicating that this patient is likely to have moderate recovery.

\section{Discussion}

Virtually all the literature on head injury has focused on the sequelae of severe and mild head injury. ${ }^{[8-17]}$ Few studies has been dedicated to patients sustaining moderate head injuries. ${ }^{[3,4]}$ Rimel et $\mathrm{al}^{[3]}$ reported that following moderate head injury only $38 \%$ made good recovery in their study compared to $45 \%$ (39/85) in our study indicating almost a similar outcome. Neuropsychological 
Table 4: Comparison of the results of the accuracy of the above mathematical model in predicting the outcome when used in the group A of 64 patients Vs. prospectively in the group B of 21 patients.

\begin{tabular}{|c|c|c|c|c|c|c|c|c|}
\hline \multirow[b]{2}{*}{ Outcome group } & \multicolumn{4}{|c|}{ Outcome in the group $A$ of 64 patients } & \multicolumn{4}{|c|}{ Outcome in the group B of 21 patients } \\
\hline & No. & $\begin{array}{l}\text { True } \\
\text { prediction }\end{array}$ & $\begin{array}{l}\text { Actual } \\
\text { outcome }\end{array}$ & $\%$ & No. & $\begin{array}{l}\text { True } \\
\text { prediction }\end{array}$ & $\begin{array}{l}\text { Actual } \\
\text { outcome }\end{array}$ & $\%$ \\
\hline $\begin{array}{l}\text { Dead or severe } \\
\text { disability }\end{array}$ & 4 & $\begin{array}{l}100 \\
(4 / 4)\end{array}$ & $\mathrm{Nil}$ & 0 & 1 & $\begin{array}{l}100 \\
(1 / 1)\end{array}$ & Nil & 0 \\
\hline Moderate recovery & 37 & $\begin{array}{l}70.3 \\
(26 / 37)\end{array}$ & $\begin{array}{l}\text { Dead } \\
\text { Good } \\
\text { recovery }\end{array}$ & $\begin{array}{l}2.7 \\
(1 / 37) \\
27.1 \\
(10 / 37)\end{array}$ & 15 & $\begin{array}{l}80 \\
(12 / 15)\end{array}$ & $\begin{array}{l}\text { Dead } \\
\text { Good } \\
\text { recovery }\end{array}$ & $\begin{array}{c}0 \\
20 \\
(3 / 15)\end{array}$ \\
\hline
\end{tabular}

No: Number of Patients \%: Percentage

batteries performed in moderately head injury patients in Rimel' series 3 months after the injury demonstrated significant deficits on all test measures ${ }^{[3]}$ while in our study nearly $40 \%$ developed neuropsychological sequelae.

CT scan features were found to be one of the important predictors in head injury in our study that is agreement with the findings of other studies. ${ }^{[18,19]}$ Hsiang et al ${ }^{[20]}$ reported that moderate head injury patients harboring acute subdural hematoma had a very poor outcome to the extent $65 \%$ died or were severely disabled and none made a good recovery as measured by the Glasgow outcome scale. Gennarelli et $\mathrm{al}^{[21]}$ and Lobato et $\mathrm{al}^{[22]}$ have reported that the type of lesion is an important factor in determining the outcome as is severity of injury. It has been reported that the causative lesion plays a significant role in determining the outcome in moderate head injuries rather than the status of the basal cisterns or midline shift especially with regards to extradural hematoma, subdural hematoma, diffuse cerebral edema and multiple lesions. ${ }^{[23]}$ An association between multiple intracerebral hemorrhagic lesions on CT scan and poor outcome was reported. ${ }^{[24-26]}$ Based upon $\mathrm{CT}$ and MRI scan findings in moderate head injuries it has been reported that isolated nonhemorrhagic diffuse axonal injury type lesions were not associated with poor clinical outcome but the hemorrhagic DAI type lesions associated with traumatic space occupying lesions had a poor outcome. ${ }^{[27,28]}$ The above studies supports our view of classifying CT scan features based only on the pathology of the lesion in moderate head injury and giving a higher value for diffuse injury and lower value for mass lesions with the lowest value given for bilateral mass lesions.

In moderate head injuries Van der Naalt et al ${ }^{[29]}$ reported that verbal response score determines the outcome instead of the GCS. In our study among the GCS parameters, verbal response achieved the highest statistical significance that is in agreement with the above finding. They also stated that diagnostic assessments such as CT scan would further increase the accuracy in predicting the outcome. ${ }^{[29]}$ It has also been reported that the presence of focal neurological signs was highly predictive of serious complications ${ }^{[30]}$ and there is negligible risk of neurological deterioration if the neurological examination is normal. ${ }^{[31]}$ Similar findings with regards to the neurological signs were observed in our study. The above findings support our equation of incorporating the verbal response, CT scan findings and neurological signs in predicting the outcome in moderate head injury.

The overall accuracy of this equation in first 64 cases in the preliminary study is around $80 \%$ while in the next 21 patients when used prospectively are $85 \%$. Hence, it is considered that the use of the mathematical model CT $\mathrm{x}(\mathrm{VR}+\mathrm{NS})$ at admission stage in cases of moderate head injury is a useful tool for reliable prediction of outcome. This is one of the very few studies to look only into the isolated moderate head injury outcome and the first study to propose an outcome model that can be used by the bedside on first day of traumatic brain injury itself. Further studies recruiting larger number of patients are needed for prospective validation of the above mathematical model in moderate head injuries.

\section{Acknowledgement}

I wish to acknowledge the Managing Trustee of PSG Hospitals, Coimbatore, Tamil Nadu, India and Managing Director of MIOT Hospitals, Chennai for permitting me to do the above work in their respective hospitals during the above period. Dr. K. J. Raman, Reader in Statisties, Loyola College, Chennai for doing the statistical analysis.

\section{References}

1. Levin HS. Neurobehavioral outcome of mild to moderate head injury. In : Hoff .J Anderson T, Cole T. Mild to moderate head injury. Boston: Blackwell Scientific; 1992. p. 52-185.

2. Teasdale G. Workshop consensus; Clinical management of mild to moderate head injury. In: Hoff J, Anderson T, Cole T. Mild to moderate head injury. Boston: Blackwell Scientific; 1992. p. 226-8.

3. Rimel RW, Giordani B, Barth JT, Jane JA. Moderate head injury: completing the clinical spectrum of brain trauma. Neurosurgery 1982;11:344-51.

4. Tabbador K, Mattis S, Zazula T. Cognitive sequelae and recovery course after moderate and severe head injury. Neurosurgery 1984;14:701-8.

5. Teasdale G, Jennet B. Assessment of coma and impaired consciousness. A practical scale. Lancet 1974;2:81-4.

6. Strub RL, Black FW. The mental status examination in neurology. Philadelphia: FA Davis Co; 1987. p. 17-85.

7. Jennet B, Bond M. Assessment of outcome after severe brain damage. A practical scale. Lancet 1975;1:480-4.

8. Liaquat I, Dunn LT, Nicoll JA, Teasdale GM, Norrie. Effect of apolipoprotein E genotype on haematoma volume after trauma. J Neurosurg 2002;96:90-6.

9. Jiang .JY, Gao GY, Li WP, Yu MK, Zhu C. Early indicators of prognosis in 846 eases of severe traumatic brain injury. J Neurotrauma 2002;19:869-74.

10. Mukherjee KK, Sharma BS, Ramanathan SM, Khandelwal N, Kak VK. A mathematical outcome prediction model in severe head injury: a pilot study. Neurol India $2000 ; 48: 43-8$

11. Signorini DF, Andrews PJ, Jones PA, Wardlaw JM, Miller JD. Predicting survival 


\section{Srinivasan et al: A mathematical model for predicting the outcome in head injury}

using simple clinical variables: a case study in traumatic brain injury. J Neurol Neurosurg Psychiatry 1999;66:20-5.

12. Srinivasan US. A mathematical model for predicting the neurobehavioral sequelae in mild head injury. In: Wen Ta Chiu. International conference on recent advances in neurotraumatology. Bologna: Monduzzi Editore; 1999. p. 281-5.

13. King NS, Crawford S, Wenden FJ, Caldwell FE, Wade DT. Early prediction of persisting post-concussion symptoms following mild and moderate head injuries. Br J Clin Psychol 1999;38:15-25.

14. King NS. Emotional, neuropsychological and organic factors: their use in the prediction of persisting post concussion symptoms after moderate and mild head injuries. J Neurol Neurosurg Psychiatr 1996;61:75-81.

15. Choi SC, Narayan RK, Anderson RL, Ward JD. Enhanced specificity of prognosis in severe head injurv. J Neurosurg 1988;69:381-5.

16. Langfitt TW, Gennarelli TA. Can the outcome from head injury be improved? . Neurosurg 1982;56:19-25.

17. Narayan RK, Greenberg RP, Miller JD. Improved confidence of outcome prediction in severe head injury. A comparative analysis of the clinical examination, multimodality evoked potentials, CT scanning and intracranial pressure. Neurosurgery 1981;54:751-62.

18. Mataro M, Poca MA, Sahuquillo J, Pedraza S, Ariza M, Amoros S, et al Neuropsychological outcome in relation to the traumatic coma data bank classification of computed tomography imaging. J Neurotrauma 2001;18:869-79.

19. Wardlaw JM, Easton VJ, Statham. Which CT features help predict outcome after head injury? J Neurol Neurosurg Psychiatr 2002;72:188-92.

20. Hsiang J, Marshall LF. Head injury. In: Swash M. Outcomes in neurological and neurosurgical disorders. Cambridge: Cambridge university press; 1998. p. $157-$ 80 .

21. Gennarelli TA, Spielman GM, Langfitt TW, Gildenberg PL, Harrington T, Jane JA, et al. Influence of the type of intracranial lesion on outcome from severe head injury. A multicenter study using a new classification system. J Neurosurg $1982 ; 56: 26-32$
22. Lobato RD, Cordobes F, Rivas .J.J. Outcome from severe head injury related to the type of intracranial lesion. A computerized Tomography study. J Neurosurg $1983 ; 59: 762-4$

23. Srinivasan US, Muthukumar N, Gajendran R, Mohansampathkumar M, Athiappan S. Influence of basal cisterns, midline shift and pathology on outcome in head injury Neurol India 1993;41:51-5

24. Fearnside M, McDougall P. Moderate head injury: a system of neurotrauma care. Aust N Z J Surg 1998;68:58-64.

25. Sweet RC, Miller JD, Lipper M, Kishore PR, Becker DP. Significance of bilateral abnormalities on the CT scans in patients with severe head injurv. Neurosurgery 1978;3:16-21

26. van der Naalt J, Hew JM, van Zomeren AH, Sluiter W.J, Minderhoud JM. Computed tomography and magnetic resonance imaging in mild to moderate head injury:early and late imaging related to outcome. Ann Neurol 1999;46:70-8.

27. Paterakis K, Karantanas AH, Komnos A, Volikas Z. Outcome of patients with diffuse axonal injury:the significance and prognostic value of MRI in the acute phase. J Trauma 2000;49:1071-5.

28. Marshall LF, Marshall SB. Outcome prediction in severe head injury. In: Wilkin RH, Rengachary SS. Neurosurgery. New York: McGraw-Hill; 1996. p. 2717-21.

29. Van der Naalt J, van Zomeren AH, Sluiter W.J, Minderhoud JM. One-year outcome in mild to moderate head injury: the predictive value of acute injury characteristics related to complaints and return to work. J Neurol Neurosurg Psychiatr 1999;66:207-13.

30. Feuerman T, Wackym PA, Gade GF, Becker DP. Value of skull radiography, head computed tomographic scanning and admission for observation in cases of minor head injury. Neurosurgery 1988;22:449-53.

31. Shackford SR, Wald SL, Ross SE, Cogbill TH, Hoyt DB, Morris .JA, et al. The clinical utility of computed tomographic scanning and neurological examination in the management of patients with minor head injuries. J Trauma 1992;33:385-94.

Accepted on 19-01-2006 